\title{
Quatro Décadas de Criação Musical para Piano
}

Ricardo Tacuchian

Review of the book GANDELMAN, Saloméa. 36 compositores brasileiros: obra para piano (19501988). Rio de Janeiro: Funarte, Relumc Dumará, 1997.

Este texto é uma resenha crítica do livro de Saloméa Gandelman, 36 compositores brasileiros: obras para piano (19501988) (Rio de Janeiro: Funarte, Relume Dumará, 1997.)

O meio artístico e acadêmico brasileiro conhece Saloméa Gandelman de longa data. Embora com um currículo inicial que sugeriria uma brilhante carreira de pianista, a discípula de Schnabel preferiu se dedicar ao magistério de piano (formou inúmeros pianistas e professores) ou à administração acadêmica (foi diretora dos Seminários de Música Pró-Arte do Rio de Janeiro e diretora e decana, respectivamente, do Instituto Villa-Lobos e do Centro de Letras e Artes da UNI-RIO; atualmente, é a coordenadora dos cursos de Mestrado e Doutorado em Música daquela Universidade). Durante todos estes anos, Gandelman conquistou uma inquestionável experiência pedagógica e administrativa, com uma sólida reputação profissional. O que o meio artístico e acadêmico 
não sabia ainda - apenas desconfiava - era do fôlego e competência musicológica da autora, revelados com tanta clareza, concisão e segurança. A pedagoga e a musicóloga se juntaram para produzir uma obra de grande envergadura na literatura musical brasileira, ao estudar 479 títulos para piano, de um total de 36 compositores brasileiros das quatro últimas décadas. A justificativa para o estudo desse repertório foi estabelecida pela autora, depois que ela fez o seguinte diagnóstico (p. 27):

"... resistência ao conhecimento das linguagens musicais contemporâneas; desconhecimento da produção musical brasileira recente para piano; desconhecimento das características composicionais e pianísticas dessa produção; dificuldade de acesso às obras (boa parte ainda manuscrita, com seus autores) e um movimento editorial restrito; ausência dessas obras nos programas de piano e de análise musical das escolas de música e conservatórios do pais e dos programas de concerto ..."

Desde o século XIX, o piano vem-se tornando um instrumento muito popular no Brasil. Inúmeros pianistas internacionais, durante o $2^{\circ}$ Império, visitaram o Rio de Janeiro e alguns fixaram residência naquela cidade. Logo, o instrumento se difundiu por todo o país, não só nos centros urbanos como também nas grandes casas rurais. Desde o Método de Pianoforte do Padre José Maurício Nunes Garcia até a extraordinária obra pianística de Villa-Lobos, passando por nomes como Carlos Gomes, Brazílio Itiberê da Cunha, Leopoldo Miguez, Henrique Oswald, Alexandre Levy, Alberto Nepomuceno, Francisco Braga, Luciano Gallet e Lorenzo Fernandez, entre muitos outros, a literatura brasileira para piano tem-se ampliado em quantidade e em qualidade. Da mesma forma, tanto no passado como no presente, o Brasil tem sido o celeiro de grandes pianistas, bastando citar os nomes de Magdalena Tagliaferro e de Guiomar Novaes, para não se estender numa lista interminável. Além disso, o piano foi um dos berços da nascente música popular brasileira, especialmente nas mãos de Ernesto Nazareth e Chiquinha 
Gonzaga. A segunda metade do século XX revelou novos compositores de grande domínio técnico, diferentes tendências estéticas, algumas com violentas rupturas com a tradição, em um número extraordinariamente elevado. É este o período que Saloméa Gandelman cobre em sua pesquisa.

O trabalho pode ser classificado no gênero "Catálogo", que apresenta determinadas peculiaridades, com um exaustivo rigor metodológico. De início, a organização geral da obra oferece ao leitor diferentes ferramentas para a consulta sob vários pontos de vista. Após um elegante prefácio, assinado por José Maria Neves, e um compacto capítulo introdutório, as obras para piano de 36 compositores são relacionadas e comentadas, em ordem alfabética por compositor ${ }^{\prime}$. Ao final, um valioso índice remissivo permite ao leitor pinçar obras para piano que possuam alguma característica em particular. Assim, Gandelman divide o repertório estudado de acordo com as seguintes dimensões: uma única mão, piano a quatro (ou mais) mãos, dois pianos, piano e fita, piano expandido, estudos, fugas e invenções, sonatas e sonatinas, tema com variações, técnica dodecafônica, notação expandida, indeterminação e atuação cênica.

No comentário das obras propriamente ditas, a autora informa, além do título e movimentos (quando procedente), o ano da composição, o local onde foi composta, a duração aproximada e a editora ou se se trata de manuscrito. Talvez limitada pelo espaço disponível para uma empresa tão grande, a autora se eximiu de fornecer outras informações que seriam úteis, tais como dedicatória, se fosse o caso, data e intérprete da primeira audição, gravações e prêmios recebidos. Os compositores já falecidos são referidos com data e cidade de nascimento, mas apenas com data de morte.

Após aqueles dados de identificação, há um breve comentário analítico e estético da obra. Aqui, Saloméa Gandelman inaugura um estilo aforismático de dizer "quase tudo" com o máximo de economia. A capacidade de síntese da autora, sem prejuízo da informação básica e do comentário lúcido, é uma das maiores 
qualidades dessa obra. Tomemos, como exemplo, o comentário que ela faz aos três movimentos (Fanfarra, Valseando e Indiozinho carnavalesco) da Mimíscula III de Guerra Peixe (p. 83):

"Ênfase no intervalo de $4^{\mathrm{a}}$ justa sucessiva e simultânea - Fanfarra. Movimento cromático do baixo, à maneira de valsa brasileira. Complementaridade rítmica entre os planos inferior e superior Valseando. Inspiração folclórica; melodia imitando a dos Caboclinhos do Recife - Indiozinho carnavalesco".

Os parâmetros explorados pelos compositores são apontados com propriedade, tais como centros tonais, registros mais explorados, texturas, densidades, harmonias, contraponto, traços nacionalistas ou universais, rítmica, caráter (humor, drama), estética, estilo, gênero, enfim, uma gama de informações que introduz qualquer um no universo estudado. Gandelman não pretende esgotar o assunto. Ela apenas sugere as características mais marcantes de cada obra e que orientarão o interessado no levantamento do repertório com determinado perfil.

A mesma síntese e a mesma precisão ocorrem quando ela comenta o tratamento pianístico da obra. Aqui, o pianista ou o professor poderá selecionar uma peça para seu repertório ou de seu aluno em função das respectivas forças técnicas do intérprete. Vejamos um exemplo de comentário pianístico no Frevo de Cláudio Santoro (p. 271):

"Oitavas, acordes, acordes quebrados, deslocamentos laterais e saltos em andamento vivo. Agrupamento irregular das subdivisões de tempo resultante de articulações fraseológicas e acentos deslocados. Brilhantismo, vigor rítmico".

Ainda neste mesmo tópico, tomemos outro exemplo que bem mostra a capacidade de síntese da informação que a autora nos oferece, quando ela descreve as questões pianísticas das VIII Variações (sobre um tema do Rio Grande do Norte) de Almeida Prado (p. 219): 
"Condução de vozes. Acentos deslocados; simultaneidade de diferentes agrupamentos das subdivisões do tempo, trama rica e variada. Superposição de mãos. Blocos amplos, extensão. Terças duplas. Pedal cuidadosamente dosado".

$\mathrm{Na}$ realidade, tanto as reflexões sobre as técnicas composicionais e as tendências estéticas como os comentários sobre os problemas pianísticos de execução respondem às perguntas que a autora faz na introdução de seu trabalho (p. 27):

- "Quais as características composicionais mais marcantes de cada uma das obras do corpus?

- Quais as exigências pianísticas básicas dessas obras e seu grau de dificuldade?"

Esses problemas são pacientemente analisados no decorrer dos 36 compositores e dos 479 títulos abrangidos pelo livro. Gandelman se reserva aos comentários estéticos, analíticos ou pianísticos, propriamente ditos, se eximindo de revelar julgamento de valor. Não que falte paixão, no decorrer do livro, aqui ou ali, mas para preservar um mínimo de isenção no estudo das obras. É a própria Saloméa Gandelman quem chama a atenção sobre esta questão (p. 27):

"Pela própria natureza do trabalho - descrição do conjunto de composições para piano desses compositores - não foram levados em conta critérios de valor ou gosto pessoal, embora a pretensa neutralidade seja um mito. Naturalmente, o grau de empatia com as obras determinou o maior ou menor interesse na formulação das análises e das informações, que pretendem ser apenas pontos de partida para investigações mais detalhada".

Como se fosse possível maior objetividade, a autora propõe uma classificação da competência necessária para vencer as dificuldades pianísticas da peça. São quatro os níveis propostos, com suas subdivisões, exceto o último nível: nível elementar (I, II 
e III), nível intermediário (I, II e III), nível avançado (I, II e III) e nível virtuosístico. Gandelman chama a atenção para a subjetividade que esta classificação pode carregar em seu bojo, pois ela varia de pianista para pianista (e, mesmo, do critério de cada professor).

Além da contribuição que 36 compositores brasileiros dará a pianistas, musicólogos e estudantes de piano, o rigor científico de que a obra se reveste torna-a um modelo para outros autores que pretendam visitar este gênero musicológico. A autora apontou com clareza os problemas a serem resolvidos e definiu e delimitou com precisão seu objeto de pesquisa. Deste modo, levantou, inicialmente, uma lista de 82 compositores, verificando, em seguida, aqueles que figuraram, pelo menos, duas vezes em programas das Bienais de Música Brasileira Contemporânea do Rio de Janeiro ou dos Festivais de Música Nova de Santos. Uma vez delimitado o objeto de pesquisa, a autora selecionou as peças para piano inseridas dentro do período em questão e que atendessem a um dos seguintes formatos: obras para piano, piano a quatro mãos, dois pianos e piano e fita. Foram excluídos Camargo Guarnieri e Francisco Mignone, que devem merecer estudos especiais pela extensão e importância de suas obras para piano. Dos autores estudados, aqueles que apresentaram a mais extensa produção pianística foram Almeida Prado (69 títulos), Osvaldo Lacerda (45 títulos), Cláudio Santoro (40 títulos) e Gilberto Mendes (31 títulos). A partir deste inventário, foi iniciado o trabalho de identificação e análise das partituras selecionadas.

Saloméa Gandelman, com seu livro, presta um enorme serviço à música brasileira para piano e à sua difusão, considerando que a imensa maioria das obras está em manuscrito ou em registro digital de posse do compositor.

Em suma, trata-se de uma obra modelar em seu gênero, pela pertinência, significado, rigor metodológico e espírito de concisão. 


\section{NOTA}

1. Os compositores estudados foram: Ernani Aguiar, Heitor Alimonda, Eduardo Guimarães Álvares, Jorge Antunes, Guilherme Baier, Lindembergue Cardoso, Sérgio Vasconcellos Corrêa, Aylton Escobar, César Guerra-Peixe, Luigi Antonio Irlandini, Bruno Kiefer, Hersz Dawid Korenchendler, Edino Krieger, Osvaldo Lacerda, Paulo Costa Lima, Ernst Mahle, José Augusto Mannis, Gilberto Mendes, Marcos José Mesquita, Ronaldo Miranda, Henrique Morozowicz, Marlos Nobre, Jamary de Oliveira, Willy Corrêa de Oliveira, José Penalva, J. A. Rezende de Almeida Prado, Marisa Rezende, Agnaldo Ribeiro, Leonardo Sá, Cláudio Santoro, Murilo Santos, Ricardo Tacuchian, Emílio Terraza, Augusto Valente, Roberto Pinto Victorio e Ernst Widmer.

Ricardo Tacuchian é compositor e regente, doutor em Música pela University of South California, ex-professor visitante da State University of New York at Albany, membro da Academia Brasileira de Música, pesquisador do CNPq e professor titular da UNI-RIO. 